\title{
Chinese Graduate Students at North American Universities: Learning Challenges and Coping Strategies
}

\author{
Jinyan Huang (Queen's University) \\ Don A. Klinger (Queen’s University)
}

\begin{abstract}
The paper investigated four Chinese graduate students' perceptions of the challenges they face and the coping strategies they use in their English academic learning at two North American universities. They reported experiencing the following seven major challenges in their academic learning: 1) financial difficulties; 2) problems in using English for academic purposes; 3) frustrations in becoming a permanent resident; 4) difficulty in adapting to the classroom learning environment; 5) lack of critical thinking skills; 6) acculturation problems; and 7) loneliness and academic anxiety. For each of the seven challenges they have developed corresponding coping strategies.
\end{abstract}

\section{Résumé}

Cet article examine la perception des défis auxquels devaient faire face quatre étudiants chinois et les stratégies qu'ils employaient pour survivre dans le milieu d'apprentissage académique anglais de deux universités en Amérique du nord. Ils ont éprouvé, disaient-ils dans leurs récits, les sept défis importants suivants: 1) des difficultés financières; 2) des problèmes sur l'usage de l'anglais pour des fins académiques; 3) des frustrations dans leurs applications pour la résidence permanente; 4) des difficultés d'adaptation au milieu d'apprentissage de leurs classes; 5) un manque d'aptitude d'esprit crituque; 6) des problèmes d'acculturation; et 7) la solitude et l'anxiété académique. Pour chacun de ces défis, ils ont développé des stratégies de survie correspondantes.

\section{Introduction}

Chinese students from the Peoples Republic of China (PRC) are the largest single group of ESL students (Canadian Bureau for International Education, 2002; Institute of International Education, 2001). Furthermore, approximately eighty percent of Chinese students currently studying at North American universities are graduate students. Generally, they have received their undergraduate education in China prior to commencing graduate school in North America. The academic learning experience of this group of Chinese graduate students has important educational implications for university administrators and educators.

Chinese graduate students arrive from a very different educational system and cultural environment. Research with ESL students studying at North American universities has indicated that Chinese graduate students experience 
considerable challenges in their academic studies (e.g., Chen, 1999; Huang, 2004; Huang, 2005; Lin, 2002; Liu, 1994; Myles, Qian \& Cheng, 2002; Wan, 2001, Zhong, 1996). These challenges come from many sources: unfamiliarity with the North American educational culture; lack of North American academic background; financial difficulties; lack of academic study skills and inadequate English proficiency. These factors negatively affect the academic study of Chinese graduate students (e.g., Feng, 1991; Huang, 1998; Huang, 2004; Huang, 2005; Sun \& Chen, 1997; Upton, 1989). However, given their generally high rate of success in academic studies and contributions to North American society (Johnson, 2001), these students do develop effective coping strategies to meet these challenges (Lin, 2002). Nevertheless, the exact nature of these challenges and the students' coping strategies have not been closely examined. Hence the purpose of this study was to investigate Chinese graduate students' perceptions of the challenges they face and the resulting coping strategies they use to support their academic learning at North American universities. The following two questions informed the study: 1 ) what are Chinese graduate students' perceptions of the factors contributing to or impeding their English academic learning, and 2) what are the corresponding strategies they use to cope with their academic learning challenges? The Confucian-Socratic framework provided a foundation for investigating the potential challenges and coping strategies faced by Chinese graduate students (Tweed \& Lehman, 2002). Activity theory was then used to analyse the set of socio-cultural, educational, linguistic, cognitive, affective, and financial challenges faced by these Graduate students (Jonassen \& RohrerMurphy, 1999). Finally, Tinto's model of student retention was used to understand and explain the in-class and out-of-class experiences of these students (Tinto, 1993). Tinto's model regarding student academic and social integration has been used by many researchers and it has a strong explanatory power in understanding student experiences (Kerka, 1995; Wortman \& Napoli, 1996).

\section{Context}

Academic learning, as argued by Tweed and Lehman (2002), varies depending on the cultural context. They proposed a Confucian-Socratic framework to analyze the influence of different cultural contexts on academic learning. Socrates (469399 BC), a Western exemplar, valued the questioning of both his own and others' beliefs, the evaluation of others' knowledge, self-generated knowledge, and teaching by implanting doubt. Socratic-oriented learning involves "overt and private questioning, expression of personal hypotheses, and a desire for selfdirected tasks” (p. 93). In contrast, Confucius (551-479 BC), an Eastern exemplar, valued effortful and respectful learning, behavioral reform, and pragmatic acquisition of essential knowledge (Tweed \& Lehman, 2002). Confucian-oriented learning involves "effort-focused conceptions of learning, pragmatic orientations to learning, and acceptance of behavioral reform as an academic goal" (p. 93).

Confucian philosophy has had a strong impact on Chinese people's viewpoints, ways of thinking, behaviours, and expereinces. Confucius believed that success was due mainly to hard work rather than ability. He also alleged that 
"behavior reform is a central goal of education because virtuous behavior can ensure individual success and societal harmony" (Tweed \& Lehman, 2002, p. 92). In respecting and obeying authorities, one demonstrates "the highest expression of the sense of justice" (Confucius, 1947, p. 332). The goal of pragmatic learning of essential knowledge was to enable individuals to competently conduct themselves within civil service jobs. When Chinese students come to North American universities, many bring a Confucian-oriented perspective to their learning, while their professors and peers may have a more Socratic orientation. Chinese students have little exposure to Western cultures and beliefs since there is little freedom to explore other cultures. Not surprisingly, these graduate students are unfamiliar and even uncomfortable with North American culture and the North American learning environment, especially for those students whose studies focus on the humanities and social sciences. These difficulties are exacerbated by financial difficulties and insufficient English proficiency that further reduces these students' ability to participate in academic and social activities (Feng, 1991; Huang \& Klinger, 2004). In particular, poor English proficiency interferes with understanding and was cited as the major reason that Chinese students rated their first-year academic learning as "not enjoyable” (Huang, 1998).

Chinese graduate students are motivated towards the completion of a higher learning academic degree at North American universities within a crosscultural or intercultural learning activity. The structure of the activity is constrained by cultural factors including conventions and social strata within the specific context (Jonassen \& Rohrer-Murphy, 1999). In order to be successful, these students need to use their knowledge and skills (tools), abide by North American culture, and collaborate with North American professors and peers. Similarly, knowledge and skill retention is related to how well students are socially and academically integrated into the institution (Tinto, 1993). According to Tinto, demographic, cognitive, and psychosocial student characteristics and interactions with the social and academic environments of the institution are the principal determinants of educational goals and institutional commitment. These characteristics and interactions account for the decision to persist or withdraw from college. Accordingly, student persistence or departure behavior is directly influenced by two dimensions of commitment, institutional and goal commitment. The former represents the degree to which an individual is motivated to graduate from a specific college or university. The latter represents the degree to which the individual is motivated, to earn a college degree in general. Institutional and goal commitments are directly influenced by external commitments and the level of academic and social integration (Wortman \& Napoli, 1996).

There is a lack of mutual understanding and common interests between Chinese students and their North American peers (Feng, 1991; Lin 2002; Wan, 2001). As an example, North Americans may talk about popular sports such as football or baseball. In contrast, Chinese students have little knowledge about such North American sports. The cultural divide can also be observed in religious beliefs and holiday celebrations. Religious beliefs are different as are the holidays celebrated by Chinese students. Chinese students do not feel the same holiday 
atmosphere during American Holidays and are often in class during Chinese holidays, away from family and friends. Hence Chinese students in North American universities cannot really enjoy any kind of holidays (Feng, 1991). Therefore, Chinese students often avoid participating in social activities in North America and have difficulties making real North American friends. Liu (1994) discovered that Chinese students in an American university transferred their Chinese cultural values and beliefs into the American context when communicating with Americans. This cultural divide can create communication problems. The principal researcher was recently asked by an American professor, likely Socratic-oriented, "Why do my Chinese students always answer 'yes' when I ask them whether they have understood my assignments or not?" (when in fact sometimes they have not totally understood). The professor was then told that in the Chinese culture it would be an embarrassment or even a shame for a Confucian-oriented Chinese student to admit not understanding a teacher in front of one's peers. A better solution would be to ask classmates after class.

Cultural differences in the classroom create anxiety and stress and negatively impact achievement. These differences begin with the unfamiliar structure and facilities of American universities (Sun \& Chen, 1997) and continue into student attitudes, classroom interactions, and teaching methodology. Upton (1989) indicated that Chinese students have a negative reaction toward American students' behaviors in classroom settings. Tardiness, questioning and challenging professors, or making jokes in class are all considered rude and disrespectful in Chinese classrooms. Chinese students also struggle with American students' selfcenteredness (Chen, 1985). "They come to the classroom as individuals, study whatever subjects they are really interested in, and do not care much what other people think of them. After class, they would never mind what their fellow students are going to do (quoted in Upton, 1989, p. 24)." In contrast, Chinese students do care what the teacher and other students think of them. If students cannot correctly answer the teacher's questions in class, they have "lost face" and feel very embarrassed and even ashamed. As a result, they are often afraid of making mistakes.

Differences in instructional styles have become the biggest challenge for Chinese students in American universities and Chinese students find it hard to adapt to these differences. Chinese classrooms lack the spirit of equality (Fu, 1991). Teachers are regarded not only as authorities in their field of study but also the students' moral mentor. Chinese teachers are very serious and tend to lecture as a teaching style. In contrast, North American teachers often use humor and varied informal teaching methods (Upton, 1989). North American teachers usually regard themselves as facilitators of learning rather than authorities of knowledge. They stress student thinking and discussion, encouraging students to be active in classroom discussions and praising critical and daring ideas (Upton, 1989). Chinese students are not accustomed to the vast amount of student participation and discussion in North American classrooms because they think too much student participation affects their understanding of the lecture (Huang, 2005). 
Interestingly, Chinese students feel frustrated that their lack of such higher-level thinking skills makes them passive learners in the classroom (Lin, 2002).

Other differences can be observed in the lack of structure of North American lectures. North American teachers rely far less on textbooks, expect students to complete extensive reading, are not afraid to become "sidetracked" into a tangential topic during a lecture, do not write detailed information on the board, and rarely summarize their lectures (Fu, 1991; Huang, 2005; Upton, 1989). These strategies are viewed by Chinese students as indicating poor organization and have been identified as a major factor negatively influencing lecture comprehension.

While a number of studies have explored Chinese students' learning challenges in North American universities, few have investigated coping strategies (Chen, 1996; Lin, 2002; Wan, 2001). Wan (2001) noted that Chinese students "take advantage of their knowledge of reading and writing in English to compensate for their insufficiency in aural and oral English.” (p. 37). Chen (1996) identified reflective thinking as the most significant strategy to cope with cultural shock. Given the lack of research regarding coping strategies, the current study included an examination of coping strategies as presented by the participants. At the same time, the study also compared these challenges and coping strategies within the American and Canadian contexts.

\section{Method}

Because the purpose of this study was to obtain in-depth information about Chinese graduate students' academic learning reality, semi-structured interviews were conducted. A random purposive sampling strategy was used to select participants because it added credibility to the study (Gay \& Airasian, 2003). A sample of four graduate students, two from an American University (participants A and B) and two from a Canadian University (participants C and D) participated in the study. Semi-structured interviews were conducted between the principal researcher and the participants to mirror the reality of their academic learning experience at these two North American universities.

At the time of the interview participant A was a Masters of Arts (MA) student majoring in Teaching English to Speakers of Other Languages (TESOL). He came to the American university to study for his MA in August 1998. He was in his fifth year of study and was preparing to graduate shortly.

Participant B was a PhD student majoring in Educational Leadership. He came to the same American university in August 1998, and started his Master's program in September. He received his MA in 2000 and then continued to work towards his $\mathrm{PhD}$ degree in the same area. He was in the final year of his doctoral program.

Participant C was a Master's student majoring in Education. She had started her graduate program at a Canadian university approximately two months before the interview. 
Lastly, participant $\mathrm{D}$ was a $\mathrm{PhD}$ student majoring in Mechanical Engineering. He started his $\mathrm{PhD}$ program at the same Canadian university in May 2002.

The interviews were conducted face-to-face with the students at the Canadian university and via telephone with those at the American university. These interviews allowed the students to describe the "reality" of their academic learning experience at these two North American universities, identifying their perceptions of the factors contributing to or impeding their English academic learning, academic learning challenges, and corresponding strategies to cope with these learning challenges. Activity Theory (Jonassen \& Rohrer-Murphy, 1999; Tolman, 1999) guided the development of the interview questions and the analyses of interview data. In order to investigate the participants' perceptions of the factors contributing to or impeding their English academic learning, responses were sorted, categorized, and analyzed under the following factors: sociocultural, educational, linguistic, cognitive, affective, and financial (Huang \& Klinger, 2004). As for the identification of their academic learning challenges and corresponding coping strategies, a coding and classifying approach was used (Gay \& Airasian, 2003). Responses relevant to these questions were grouped together and then categorized and analyzed according to the recurring themes.

\section{Results And Discussion}

The results of the interviews are summarized below. Six major factors affecting the four Chinese graduate students' cross-cultural academic learning in these two North American universities were identified. Both academic learning challenges and coping strategies were investigated. Seven major academic learning challenges were found: 1) financial difficulties; 2) problems in using English for academic purposes; 3) legal frustrations (resident status); 4) difficulty in adapting to the classroom learning environment; 5) lack of critical thinking skills; 6) acculturation problems; and 7) emotional difficulties (loneliness and anxiety). For each of the seven challenges the students developed corresponding coping strategies.

\section{Financial Difficulties}

Financial difficulties were ranked as one of the top-three factors negatively affecting academic study for these students at both of these North American universities. Insufficient financial support from both universities created great challenges for them to complete their graduate studies. In response, these students found it necessary to find extra work within their academic institutions. This work involved increased research commitments or non-related work, for example, as a language translator or a janitor. These students also found it necessary to spend money very cautiously. As stated by participant A "I only buy things that I have to buy, but I never buy stuff beyond my budget or financial ability.” Participant D went further saying, "sometimes I have to control my desire for purchasing things.” These financial constraints also affected other pursuits as well. As noted by participant B, a PH.D student, "We don’t have money for traveling. We have 
never traveled in the US.” Similarly, as noted by participant D, “I don’t have more money for recreational activities."

\section{English Language Problems}

Along with financial difficulties, these graduate students ranked insufficient English proficiency as one of the top-three factors negatively affecting their academic study. Although each of these students had obtained very high TOEFL scores, they did not feel confident in their English language proficiency. They all reported having difficulties in using English for academic purposes, in particular, speaking and writing skills, which they considered to be weak. These students found it difficult to participate in oral presentations, as well as class discussions. In addition, the academic writing process was found to be challenging, especially in terms of format and expectations.

The simplest strategy used to cope with these demands is best summarized by participant D, "we may spend more hours preparing a research project than native Canadians.” At the same time, English listening and speaking skills would best be improved by "talking to native Americans whenever it is possible." In terms of improving reading efficiency, established strategies that include "always paying attention to the key words, the titles, the subtitles, the introduction and the summary, the topic sentence, the first paragraph, and the last paragraph" were identified. Given the importance of academic writing, these students identified a variety of coping strategies including reading sample journal articles before writing, understanding North American academic writing formats such as APA, making use of English writing centers on campus, and continual paper revisions.

\section{Legal Frustrations and Permanent Residency}

Many Chinese graduate students are interested in obtaining permanent residence status in North America believing that, as stated by participant A, "America is more developed. People make more money. There is more privacy. The environment is less polluted. People can afford cars. There is more freedom, including freedom of speech." However, the residency process can be extremely difficult, especially after the September 11 attack. For participant A, the legal frustrations in obtaining permanent residency status was the number one factor negatively affecting his graduate study.

For these graduate students, extending their length of stay in North America appears to be the best method to cope with these legal issues. Like many other Confucian-oriented Chinese students, these students combine this with their future plans. Participant A reduced the intensity of his graduate study program and found part time work. Participant B recognized that, even with residency, he would have difficulties obtaining employment in his field. Believing that two PH.D degrees would help ensure employment in North America, he has applied and been accepted into another PH.D graduate program, one he will start once he defends his current dissertation. In contrast, participant $\mathrm{C}$ did not show any interest in obtaining a permanent resident status in Canada believing it would be 
almost impossible for her to find a job in Canada. Participant D has applied for permanent residency in Canada with the belief that "having a Canadian permanent resident status will help me go anywhere else, for example, the US, England, and Europe.”

\section{Adapting to the Classroom Learning Environment}

Graduate studies in the humanities and social sciences tend to be more society specific than those in engineering or science. Hence Chinese graduate students in the humanities or social sciences have more challenges adapting to the North American classroom environment than those in engineering or science (Huang, 2005). The three social science Chinese graduate students in the study noted the greatest classroom challenges. Based on their responses, the main differences between the North American and Chinese classroom learning environments can be summarized in three parts. First, the form of class organization was viewed as very different. They stated that Chinese teachers tend to organize a class in a more formal way or in a step-by-step format, whereas, North American teachers prefer a more informal and casual manner in organizing a class. Second, the students' and teachers' roles were found to be different. These graduate students noted a diminished role of the North American professor coupled with an increased role for students. As noted by participant A, "the [North American] teacher doesn't play a critical role in the classroom. The students are playing the most important role in the classroom." Participant B went further noting that "in China, teachers take the full responsibility in the classrooms, they use the cramming method. The teachers mainly lecture in class. Students are very passive. They just listen to the teacher. The teachers do not encourage students' participation. Here things are quite different. Teachers encourage students to think. Students' participation is highly encouraged here. They are motivated to join in the class discussions." Because of these differences, the graduate students commented that the North American professor is a stimulator, a supporter and a helper in the students learning process. In contrast, Chinese professors are givers, and students are receivers. In supporting the North American perspective participant B stated that "In Chinese classrooms, teachers talk too much. They do not encourage students to actively learn, but passively accept."

Finally both the teacher and students have different expectations. In Chinese classrooms, students expect their teachers to give detailed explanations about each topic, because "teachers are regarded as the symbols of knowledge, they are authorities" (participant B). Teachers expect their students to be attentive listeners. But in North American classrooms, "students are expected to have read all the required materials before they come to the classrooms. The teacher can ask questions according to the materials, and sometimes explain some difficult and important points. The teacher is only an assistant” (participant A). Students can expect their teachers to give them opportunities to ask questions, express their ideas, and to discuss and debate these ideas.

In response to these challenges, the study participants noted the importance of learning to interact with North American students, forcing 
themselves to adapt to the North American classroom environment, and spending more preparation time. Participant A was fortunate to meet with a North American student who had previous experience with Chinese students. This student involved participant A in small group discussions and would continually ask participant A to express his questions or ideas. In the absence of peer support, it was the student's responsibility to "take full responsibility of learning; to be an active learner; spend more time before classes preparing; read extensively about a topic; [and] ask questions whenever it is possible in class" (participant B). These students also found that traditional strategies helped them to prepare for the North American classroom learning. Participant B stated that "learning strategies I acquired in China are still effective here in America." These included note taking, memorization of basic concepts, pre-class reading, self study, and review. The demands of these expectations are best summarized by participant $\mathrm{D}$ noting that "in Canada, I have to be active all the time."

\section{Lack of Critical Thinking Skills}

Unlike Socratic-oriented North American students, Confucian-oriented Chinese students are taught to respect and obey authorities. In Chinese culture, teachers are regarded as the symbols of knowledge and they are the authorities over students. As a result, Chinese students are not taught to be critical, an essential requirement in the North American context. These graduate students found it difficult to be critical when reviewing journal articles since books and published papers are viewed as sources of authority in the Chinese system.

In order to become more Socratic-oriented, Chinese students need to learn critical thinking skills. Yet, even after six years of experience in an American University, participant B explained that it was still not easy for him to learn critical thinking skills. He believed that he was beginning to look at things from different perspectives and was finding the courage to challenge his cultural values and concluded "Critical thinking is what I learned from my cross-cultural learning experience in America. I can get benefit from it all my life. Things cannot develop without critical thinking." Reflecting the Chinese notion of pragmatism, participant A identified a "when in Rome" approach, concluding that "I am now a student in an American university. I need to behave and think like an American. I need to consider things with multiple perspectives. I have to criticize other people's ideas or viewpoints in order to survive in this academic culture.”

\section{Acculturation Problems}

Due to their cultural and linguistic differences, the four Chinese graduate students experienced acculturation problems in both of these two North American universities. For example, they all found it very hard to make real friends in North America. Although their North American classmates were very nice to them, they were unable to develop true friendships with them. In addition, financial and language difficulties also prevented these students from participating in social activities. These challenges all function to slow down their acculturation process in North America. 
Acculturation problems were addressed using the three W's: 1) forget who you are; 2) remember where you are, and 3) do what other people do. Participant B explained that Chinese students should forget that they are from another culture. If they always isolate themselves from North Americans and consider themselves outsiders, they will never get to know North American culture. In terms of making friends, participant $\mathrm{C}$ mentioned that Chinese students should treat themselves as equally as they treat North Americans and show interest in communicating with them. Participant D added that Chinese students should always remember that they are in North America. They need to take an active attitude toward social activities. Participant A further explained that Chinese students need to do what other people do in North America. For example, celebrate Thanksgiving and Christmas as North Americans do. If Chinese students respect North American culture, North Americans will surely accept Chinese culture.

\section{Emotional Difficulties}

Emotionally, all of the Chinese graduate students identified two major difficulties, loneliness and anxiety. Being far away from their parents and friends, their daily life is full of loneliness. Participant B's description is a representative example: "My daily life is very boring. I spend most of my time at school, taking classes, studying in the library, etc.” Not surprisingly, feelings of loneliness were more pronounced when the students talked about family or holiday celebrations. Such loneliness was found to increase stress and negatively impact schooling. Participant D identified a common problem explaining that "I feel very lonely and the loneliness of course affects my emotion. When I don't feel emotionally comfortable, I cannot concentrate on my study here.” This only further increased the anxiety of the students as they continued to be anxious about finishing class assignments, writing term papers, and doing research.

Community participation was viewed as the best way to address loneliness, including on campus activities, joining organizations (e.g., the Chinese Students and Scholars Association and International Students Association). The students also found that it was important to take the opportunity to seek help. The only direct strategies to deal with anxiety were to adjust learning methods and strategies and be good at time management.

\section{Further Coping Strategies}

The graduate students were asked to use their own experience to provide three suggestions for future Chinese students coming to North America for graduate studies. These strategies generally mirrored responses to the challenges above. Nevertheless, the most important strategies focused on early and careful preparation including obtaining English skills, securing financial support, and understanding the cultural differences before coming to North America. The ability to quickly adapt to the North American culture and learning environment was viewed as a key to success. 


\section{Conclusion}

This study investigated both the learning challenges and coping strategies of four Chinese graduate students at two North American universities. Although limited in breadth, the methodology provided an in-depth discussion of the views and experiences of these students. Future research in other university settings and other students would help to expand upon the findings of the current study. It would also be valuable to compare the findings of this study to the experiences of North American professors who teach or supervise Chinese graduate students. Within this context, the findings of the current study support previous research identifying factors affecting Chinese students. Further, the study has served to identify coping strategies used by these graduate students.

Seven major academic learning challenges were identified along with their corresponding coping strategies. Similar to the findings of Feng (1991), financial difficulties remain one of the top challenges for these Chinese students. Careful budgeting and cautious spending are important financial management strategies. Similarly, problems using English for academic purposes continue to pose academic challenges. Several coping strategies were identified to help increase English academic listening, speaking, reading, and writing skills. These strategies focused largely on becoming more active in the classroom and doing more preparatory class work. The North American learning environment also continues to be a challenge. This is best viewed in the difference between the Confucian and Socratic philosophies of learning. In beginning to adjust to the North American learning environment, these graduate students seem to now favor the Socratic-oriented North American classroom learning environment. They appreciate the need to investigate alternative perspectives and develop critical thinking skills. Nevertheless, such skills remain a challenge. The "when in Rome" approach was identified as a successful strategy to address such challenges and not surprisingly, it also appeared to help support the acculturation process, forcing the students to adjust to the North American context. In spite of their attempts to acculturate, Chinese graduate students continue to express feelings of loneliness and use participation in activities or local associations to help address this challenge. Previously unreported, these graduate students expressed frustration with the challenges they faced as they attempted to obtain permanent residency. It is not known whether this is a result of an increase in the desire of Chinese students to remain in North America or if it is due to changing security policies in the wake of September 11. This frustration has led students to find ways to increase the length of their Educational experience or begin to look for other future options.

In spite of the different geographic context and the variety of experiences of the students, the results of the study showed no important differences across graduate program and country of study. All participants experienced similar challenges in their academic learning processes in North America, although some of their coping strategies for certain challenges differed slightly. The results are important for those Chinese students who are currently completing or hope to begin their graduate studies within the North American context. The results also 
have implications for professors who are responsible for these students. It is hoped that the results of this study will not only help students but also professors begin to understand the challenges that Chinese students can be expected to face in North American Universities and the coping strategies that can be used to ameliorate these challenges.

\section{References}

Canadian Bureau for International Education. (2002, April 15). International student numbers hit record high, but Canada offers dwindling support for African students. Retrieved October 28, 2002 from : http://www.cbie.ca/news/index_e.cfm?folder=releases\&page=rel_2002-04-15_e

Chen, C. P. (1999). Common stressors among international college students: Research and counseling implications. Journal of College Counseling, 2, 49-65.

Chen, S. F. (1996). Learning multiculturalism from the experiences of international students: the experience of international students in a teacher training program. Paper presented at the Annual Meeting of the American Educational Research Association. New York, NY. (ERIC Document Reproduction Service No. ED 398177)

Chen, T. H. (1985). Cultural differences in classrooms: A Comparison of Chinese and U.S. schooling. Unpublished manuscript.

Confucius. (1947). The wisdom of Confucius. In S. Commins \& R. N. Linscott (Eds.), Man and man: The social philosophers (pp. 323-358). New York: Random House.

Feng, J. H. (1991). The adaptation of Students from the People's Republic of China to an American Academic Culture. Reports (ERIC Document Reproduction Service No. ED 329833).

Fu, D. L. (1991). A process classroom through the eyes of an outsider. Language Arts, 68, 121-123.

Gay, L. R., \& Airasian, P. (2003). Educational research: Competencies for analysis and applications. New Jersey: Prentice Hall.

Huang, J. (1998). Students' learning difficulties in a second language speaking classroom. Paper presented at the Annual Meeting of the American Educational Research Association, San Diego, CA. (ERIC Document Reproduction Service No. ED 420193)

Huang, J. (2004). Voices from Chinese students: Professors' use of English affects academic listening. College Student Journal, 38(2), 212-223.

Huang, J. (2005). Challenges of Academic Listening in English: Reports by Chinese Students. College Student Journal, 39(3), 553-569. 
Huang, J., \& Klinger, D. (2004). Factors affecting Chinese graduate students' crossculturallearning at North American universities. Paper presented at the Annual Conference of the Comparative and International Education Society of Canada. Winnipeg, Manitoba.

Institute of International Education. (2001, May 16). 98/99 opendoors on the Web.

[Selections from the book], New York. Retrieved June 15, 2002 from http://www.opendoorsweb.org/Lead\%20Stories/international_studs.htm

Johnson, J. M. (2001). Human resources contributions to US science and engineering from China. SRS Issue Brief. (ERIC Document Reproduction Service No. ED 449026)

Jonassen, D., \& Rohrer-Murphy, L. (1999). Activity theory as a framework for designing constructivist learning environments. Educational Technology, Research \& Development, 47, 61-79.

Kerka, S. (1995). Adult learner retention revisited. Eric Digests, (ERIC Document Reproduction Service No. ED 389880). Adult Career and Vocational Education: Columbus, $\mathrm{OH}$.

Lin, L. (2002). The learning experiences of Chinese graduate students in American social sciences programs. Paper presented at the Annual Conference of the Comparative and International Education Society. Orlando, FL. (ERIC Document Reproduction Service No. ED 474163)

Liu, D. L. (1994). Deep sociocultural transfer and its effect on second language speakers' communication. Paper presented at the annual meeting of the Teachers of English to Speakers of Other Languages, Maltimore, MD.

Myles, J., Qian, J., \& Cheng, L. (2002) International and new immigrant students' adaptations to the social and cultural life at a Canadian university. In S. Bond \& C. Bowry (Eds.) Connections \& Complexities: The Internationalization of Canadian Higher Education, Occasional Papers in Higher Education, Vol, 11, Winnipeg, Center for Research and Development in Higher Education.

Sun, W., \& Chen, G. M. (1997). Dimensions of difficulties Mainland Chinese students encounter in the United States. Paper presented at the $6^{\text {th }}$ International Conference in Cross-Cultural Communication, Tempe, AZ. (ERIC Document Reproduction Service No. ED 408635)

Tinto, V. (1993). Leaving college: Rethinking the causes and cures of student attrition. Chicago: The University of Chicago Press.

Tolman, C. (1999). Society versus context in individual development: Does theory make a difference? In Engestrom, Y, Miettenin, R., \& Punamaki, R. (eds.) Perspectives on Activity Theory. New York: Cambridge University Press.

Tweed R. G., \& Lehman, D. R. (2002). Learning considered within a cultural context. American Psychologist, 57(2), 89-99.

Upton, T. A. (1989). Chinese students, American universities, and cultural confrontation. MinneTESOL Journal, 7, 9-28.

Wan, G. F. (2001). The learning experience of Chinese students in American universities: A cross-cultural perspective. College Student Journal, 35, 28-44.

Wortman, P. M., \& Napoli, A. R. (1996). A meta-analysis of the impact of academic and social integration on persistence of community college students. Journal of Applied Research in the Community College, 4(1), 5-21.

Zhong, M. (1996). Chinese students and scholars in the U. S.: An intercultural adaptation process. Paper presented at the $82^{\text {nd }}$ Annual Meeting of the Speech Communication Association, San Diego, CA. 
Jinyan Huang, who received his MA in TESOL from Brigham Young University, is currently a PhD candidate at the Faculty of Education, Queen's University in Canada. He has over 10 years' experience of teaching English as a foreign/second language in both China and America. His research focuses are assessment and evaluation, English for academic purposes, and cross-cultural learning.

Don Klinger $(\mathrm{PhD})$ is an assistant professor of assessment and evaluation in the faculty of Education at Queen's University. He is one of the founding directors of the Assessment and Evaluation Group. His research focuses on the quantitative methodology and the psychometric qualities and policy implications of large scale testing.

\section{Note:}

In Volume 35, number 1, Thomas Varghese \& Daniel P McCusker's article "On Globalization and Ethnomathematics," the authors wish to acknowledge $\mathrm{K} \mathrm{L}$ Kamath for Fgure 1: A mother training her daughter to draw kolam. This picture first appeared in (Ascher, M. (2002). The kolam tradition. American Scientist 90:1, 56-63). 